BULLETIN Bulletin hispanique

HISPANIQUE Université Michel de Montaigne Bordeaux

112-1| 2010

Actes du Colloque « langue, littérature, littéralité »

\title{
Le langage des larmes dans La Dorotea de Lope de Vega
}

Marta Cuenca-Godbert

\section{(2) OpenEdition}

Journals

Édition électronique

URL : http://journals.openedition.org/bulletinhispanique/1123

DOI : 10.4000/bulletinhispanique. 1123

ISSN : 1775-3821

Éditeur

Presses universitaires de Bordeaux

Édition imprimée

Date de publication : 1 juin 2010

Pagination : 149-168

ISBN : 978-2-86781-692-5

ISSN : 0007-4640

Référence électronique

Marta Cuenca-Godbert, "Le langage des larmes dans La Dorotea de Lope de Vega », Bulletin hispanique [En ligne], 112-1 | 2010, mis en ligne le 01 juin 2013, consulté le 19 avril 2019. URL : http:// journals.openedition.org/bulletinhispanique/1123; DOI : 10.4000/bulletinhispanique.1123 


\title{
Le langage des larmes dans La Dorotea de Lope de Vega
}

\author{
Marta Cuenca-Godbert \\ GRIAL
}

Lope de Vega érige La Dorotea (1632) en tombeau de sa maîtresse Marta de Nevares, mais aussi à sa propre trajectoire poétique par l'utilisation du champ sémiotique des larmes.

Lope de Vega hace de La Dorotea (1632) un homenaje a su amada Marta de Nevares y también a su propia trayectoria poética utilizando el campo semiótico de las lágrimas.

Lope de Vega writes 'La Dorotea' (1632) in honour of his last beloved mistress Marta de Nevares but also in honour of his own poetic career, through the use of the semiotic field of tears.

Mots-clés : La Dorotea - Sémiotique - Larmes.

Tengo los ojos niños y portuguesa el alma.

La Dorotea, IV, 1.

A DOROTEA, dernière grande ouvre en prose de Lope, sa "muse
posthume " comme il la désignait dans la Égloga a Claudio ${ }^{1}$, contient comme on sait un hommage à sa dernière maîtresse, Marta de Nevares,

1. «Póstuma de mis musas Dorotea, I y por dicha de mí la más querida, / última de mi vida I pública luz desea» (Lope de Vega, "Égloga a Claudio ", Rimas humanas y otros versos, Barcelona, Crítica, 1998, p. 712-713).

$B H i$, Tome 112 , nº 1 - juin 2010 - p. 149 à 168. 
morte peu avant la publication en $1632^{2}$. Aux larmes votives des amours réelles s'ajoutent celles de la fiction des amours finissantes de Dorotea et Fernando. Nadine Ly, lorsqu' elle dirigeait ma thèse de doctorat, suggérait que La Dorotea épousait partiellement et souplement la "chronologie " des traumatismes majeurs de Lope : la trahison amoureuse d'Elena Osorio, le triomphe de la nueva poesía et de son rival Góngora, et la mort d'Amarilis qui apparaît diffuse partout. Motif récurrent - larmes de deuil, larmes de rupture -, les perles lacrymales, qui peuvent correspondre à plusieurs états d'âme, appellent un complément distinctif, mais elles sont investies par le poète d'une valeur de signe comme le remarque Roland Barthes :

Les larmes sont des signes, non des expressions. Par mes larmes, je raconte une histoire, je produis un mythe de la douleur [...] : en pleurant, je me donne un interlocuteur emphatique qui recueille le plus «vrai » des messages, celui de mon corps, non celui de ma langue ${ }^{3}$.

Capables d'aimanter plusieurs niveaux de signification, les larmes deviennent un langage. Au Siècle d'Or, en effet, l'âme sensible apparaît comme une âme d'élite et les larmes s'érigent en lieu commun littéraire ${ }^{4}$. Dans La Diana, Jorge de Montemayor indique que les larmes versées avant et après les expositions des différents casos de amor coulent abondamment par obligation, comme un ingrédient nécessaire : " [...] la hermosa Selvagia començó a derramar muchas lágrimas, y los pastores le ayudaron a ello por ser un oficio de que tenian gran esperiencia " 5 . José Antonio Maravall indique par ailleurs que :

2. La mort de Marta de Nevares a entrainé quelques modifications dans la composition de l'œuvre, notamment l'inclusion des quatre barquillas, comme le remarque Edwin Morby : "Estas cuatro poesías [...] son compuestas con los trozos de diálogo correspondientes en los pocos días transcurridos entre la muerte de doña Marta (7 de abril) y la aprobación del censor ( 6 de mayo)." (Lope de Vega, La Dorotea, Madrid, Clásicos Castalia, 1980, p. 10. Désormais La Dorotea).

3. Roland Barthes, Fragments d'un discours amoureux, Paris, Seuil, 1977, p. 215.

4. Danielle Roth indique que l'iconographie européenne porte la marque d'un changement de perspective quant à la considération des larmes, en raison de la vague de mysticisme venue d'Espagne : "Ainsi l'image du mélancolique, les yeux baissés vers la terre, le regard vide et le cœur affaissé, la tête appuyée sur le coude, va céder la place à celle des yeux pleins de larmes et levés vers le ciel " (Danielle Roth, Larmes et consolations en France au XVII siècle, Lyon, Éditions du Cosmogone, 1997, p. 82). Elle ajoute que «Les larmes d'émotivité comme celles des poètes et des musiciens bénéficient d'une grande tolérance. " (Ibid., p. 88).

5. Jorge de Montemayor, La Diana, Barcelona, Crítica, 1996, p. 20. 
Las lágrimas que con frecuencia aparecen en el Quijote y de las que [...] no querrá el caballero que se olvide aquel que escriba la historia de sus hechos, son ya un motivo literario en la época y representan un externo testimonio de la bondad de corazón del hombre, tal como se le concibe en su natural manera de ser $^{6}$.

Les larmes tissent alors un réseau de métaphores qui mettent en relief leur caractère précieux et intarissable : elles deviennent des perles, du sang, du parfum, des miroirs de l'âme, une mer, une fontaine, une rivière... Le topos apparaît dans La Dorotea décliné sous tous ces aspects : les signifiants lágrima(s) et llanto(s), mais aussi tous les dérivés de llorar et les métaphores topiques qui y sont associées. Le recensement des occurrences qui composent le motif poétique des larmes ainsi que l'étude des circonstances de leur emploi mettent en évidence la configuration de leur langage, objet des lignes qui suivent. Il apparaît aussi que ses différents niveaux de signification culminent dans un concepto : le tombeau de larmes figuré dans le sonnet du phénix, à la scène 1 de l'Acte IV.

\section{LES LARMES OU LA POÉTIQUE DE L'ÉPANCHEMENT}

Les larmes, leur présence, leur effet, la stratégie suivie par les amants pour en verser ou les retenir, tissent un réseau sémiotique diffus. Un relevé des occurrences de lágrima(s) et des périphrases entretelas de la risa, fuentes de mis ojos, espejos del alma, de llorar, de ses formes conjuguées, et des périphrases comme deshacer los ojos ou llenar de agua, de llanto(s) et des quelques substituts et métaphores topiques comme perlas, mar, suspiros, pucheros met en évidence que les apparitions sont relativement peu nombreuses : 127 au total (sur un nombre de mots total d'un peu plus de 74000 ), dont 82 dans les parties dialoguées et 45 dans les poèmes (sur près de 2000 vers) ${ }^{7}$. Il en résulte que les larmes, constamment présentes, ont en réalité une prégnance quantitative discrète et distillée.

Les larmes interviennent dans des circonstances diverses. Tantôt elles permettent de libérer le poète de ses rancœurs littéraires, tantôt ce sont les larmes du movere à différents niveaux, construits en miroir : larmes comiques, larmes sincères, mise en scène des larmes.

6. José Antonio Maravall, Utopia y contrautopía en el Quijote, Madrid, Visor Libros, 1976, p. 177.

7. Voir en annexe le relevé exhaustif. 
La première occurrence du mot lágrimas apparaît dans le Prologue " $A l$ teatro ", à la fin du règlement de comptes littéraires qui clôt le propos. Lope fait allusion à "quien ya queda esperando que entretenga la risa de los príncipes soberanos con las lágrimas de la honra $"{ }^{8}$, c'est-à-dire ceux qui ont obtenu les postes les plus hauts placés au prix de leur honneur. Cette utilisation des larmes pour renvoyer à l'honneur en lambeaux de ses ennemis et, en miroir, au sien intact trouve un écho dans d'autres passages où Lope règle ses comptes littéraires ou poétiques, notamment dans " A mis soledades voy " :

\author{
$Y$ algunos, inobedientes \\ A la vergüenza y al miedo, \\ Con las prendas de su honor \\ Han trocado los efectos. \\ Virtud y filosofía \\ Peregrinan como ciegos; \\ El uno se lleva al otro, \\ Llorando van y pidiendo 9 .
}

L'expression "lágrimas de la honra " devient comme le signe de l'encre où la plume plonge pour écrire sa révolte et son indignation : l'honneur est renversé, la vertu et la sagesse sont en lambeaux et en larmes. Mais les pleurs, par le recours au verbe llorar, peuvent avoir une valeur différente: ils sont également employés dans la scène de commentaire métalittéraire du sonnet cultidiablesco (IV, 3), pour montrer l'absurdité des métaphores de la poesía nueva:

\title{
¡Qué dulce almíbar masco \\ Cuando lleno de cólera me rasco! \\ Porque parece, aunque después lo lloro, \\ Que ensarto por las uñas granos de oro ${ }^{10}$.
}

Julio explique d'abord le processus analogique à l'œuvre dans " sarna de oro" pour désigner le blé : la gale provoque une éruption cutanée, de même que le blé a des grains; le poète a ensuite ajouté l'or pour la couleur. Julio récite ce quatrain burlesque sur le plaisir de se gratter, ironiquement cité comme une source érudite, pour montrer à quel point les images mal construites ont une piètre qualité poétique. Lope n'utilise que trois fois

\footnotetext{
8. La Dorotea, p. 63.

9. La Dorotea, p. 99.

10. La Dorotea, p. 383.
} 
les larmes comme instrument de condamnation morale ou de vengeance poétique, privilégiant pour l'humeur lacrymale une fonction émotive.

Les larmes sont massivement investies d'un pouvoir émotif à plusieurs niveaux en contrepoint les uns des autres : elles apparaissent comme comiques, sincères ou mises en scène. Les larmes à effet comique sont déversées par Gerarda, chaque fois qu'elle veut obtenir un cadeau de don Bela. Ainsi, aux scènes 1 de l'acte II et 2 de l'acte $V$, les personnages ironisent sur ses pleurs faussement dévots :

Bel.: ¿Por eso lloras [porque don Bela pregunta por el intento de suicidio de Dorotea]?

Ger.: Soy tan devota, que en hablando en el Señor, no puedo contener las lágrimas.

Lau.: Todo aquello es vino.

Bel.: No llores, madre.

Lau.: Sálese el cuero ${ }^{11}$.

Bel.: Madre, luego lloras; no he visto ojos tan tiernos. Dale cuatro reales, Laurencio ${ }^{12}$.

À la scène du banquet chez Dorotea (II, 6), Gerarda verse des larmes d'ivresse lorsqu'elle évoque le sort de son époux poursuivi par la justice ${ }^{13}$ :

Teo.: Gerarda, no bebas más, que dices desatinos. $Y$ en otra parte pensaran que era verdad lo que dices.

¿Para qué lloras?

Ger. : Porque fue crueldad llevarle a galeras.

$[\ldots]$

Ger. : "Este tu hijo don Lope, ni es miel, ni es hiel, ni vinagre, ni arrope".

Cel. : En los ojos tienes eso postrero, como has llorado.

En miroir aux larmes feintes et comiques, les larmes sincères et pathétiques caractérisent le personnage de Marfisa. Elles apparaissent dans le texte comme l'élément déclencheur du revirement amoureux final de Fernando. L'amant utilise son pouvoir de séduction sur Marfisa, dont il est certain de l'attachement, pour lui soutirer de l'or et pouvoir partir à Séville (I, 6) :

11. La Dorotea, p. 147.

12. La Dorotea, p. 418.

13. La Dorotea, p. 204, p. 210. 
Fer.: [...] ¿Qué tienes? ¿Lloras por mí o por el muerto?

Mar.: Lloro por entrambos.

Fer.: Mira si tienes qué darme; que me voy a Sevilla mientras pasa esta furia; porque temo que sepan quién lo ha hecho, o me conozca el que ha quedado vivo.

[...]

No llores, Marfisa mí; que no acertaré a partirme. Porque no hay rémoras para detener un alma como las lágrimas de lo que se adora.

Mar.: En tu rostro las estampo, a efeto de que te acuerdes que las lloraron mis ojos casi en los tuyos, por engañarme de que eran tuyas.

Fer.: Alguna mía se ha mezclado en ellas, y yo te juro que las que me has puesto han hecho en mi rostro las letras de tu nombre. Pero ¿qué esclavo trujo en el mundo hierros de diamantes? Yo me parto ${ }^{14}$.

Lorsqu'il raconte cette scène à Felipa et à Dorotea masquée, aux jardins du Prado (IV, 1), Fernando associe cyniquement son mensonge aux larmes vraies de Marfisa, ces "perles» qu'elle lui offre avec son or :

Fer.: Fingi en mi casa que habia la noche antes muerto un hombre-y decia verdad, si era yo el muerto -, y que era fuerza ausentarme o caer en manos de la justicia. Diome Marfisa el oro que tenía y las perlas de sus lágrimas, y con él me parti a Sevilla.

Fel. Brava resolución.

Fer. De hombre de bien ${ }^{15}$.

Il n'est pas l'amant qui emporte avec lui l'âme de celle qu'il aime, en l'occurrence Dorotea, qui l'a trahi et qu'il oublie vite en arrivant à Séville, et l'amoureuse Marfisa dont il laisse les larmes derrière lui et ne prend que l'or. Mais lorsque cette même Marfisa découvre le mensonge et lui en fait le reproche, Fernando, à présent las de Dorotea, se dit réellement touché au cœur par ses larmes (IV, 8) :

Mar.: [...] ;Mal hayan mis pensamientos, mis firmezas y cuanto he padecido por con mis tios y con mis...!

Jul.: No le dejaron acabar las lágrimas. ¿Qué la miras? ¿Por qué no hablas? ¿Por qué no la consuelas? También llora Clara y yo estoy consultando los pucheros, si me estarán bien con tantas barbas. [...]

14. La Dorotea, p. 128-129.

15. La Dorotea, p. 326. Estimant son honneur en danger, après la trahison de Dorotea, Fernando justifie ainsi cyniquement sa conduite peu honnête vis-à-vis de Marfisa. 
Mar.: [...] Muchas lágrimas me cuestas, Fernando, muchos trabajos, dulce enemigo mío. [...]

Fer.: Espera, señora, espera. Por lo menos, no te vayas llorando. [...]

Fer.: [Con el amor de Marfisa] se me ha quitado [el de Dorotea]. [...] $Y$ como quien para que una cosa se limpie la baña en agua, asi lo quedé yo en sus lágrimas de mis deseos. [...]

Jul.: Harás que me vuelva loco y que diga que la filosofía del amor no está entendida en el mundo, pues tantos amorosos afectos, desmayos, ansias, locuras, desesperaciones, celos, deseos y lágrimas han tenido templanza en su mismo centro, lo que parece imposible ${ }^{16}$.

Les larmes sincères de Marfisa servent de révélateur, en négatif aux larmes mises en scène dans les amours finissantes de Dorotea et Fernando.

Le recours le plus fréquent aux larmes, en effet, revient au couple protagoniste. Les larmes apparaissent comme un signe de tourments amoureux pour convaincre l'amant d'un événement tragique. Elles sont toujours utilisées de façon littéraire par les amants, qui ont recours à des métaphores topiques pour les désigner. Lorsque Dorotea va voir Fernando pour lui annoncer sa rupture forcée, elle baigne son visage de larmes comme un élément annonciateur d'une tragédie :

Fer.: ;Oh Andrómeda del famoso Ticiano! Mira, Julio, iqué lágrimas! Parece azucena con las perlas del alba. Desviale los cabellos, Celia; veámosle los ojos, pues se deja mirar el sol por la nube de tan mortal desmayo. [...]

Dor.: [...] ¡Ay Dios! ¡Ay de mí! Déjame deshacer estos ojos, pues ya no son tuyos; no hay que respetarlos, no me ha de gozar con ellos quien ella piensa, porque verá en sus niñas tu retrato, que sabrá defenderlos. [...]

Fer.: ¿Pues para ocasión de tan poca importancia tanto sentimiento, Dorotea? Vuelve a serenar los ojos, suspende las perlas, que ya parecian arracadas de sus niñas. [...] Vete, mi bien, que es tarde. [...]

Dor.: ¿Por qué no volveré a ver [tu casa]?

Fer.: Porque te vas a las Indias, y hay mar en medio.

Dor.: El de mis lágrimas.

Fer.: Las de las mujeres son entretelas de la risa. No hay tempestad en verano que más presto se enjugue ${ }^{17}$. 
La tragédie initiale se renverse en comédie : aux perles sur un teint de lys (" azucena con las perlas del alba ») succède l'image peu flatteuse des larmes, transformées en pendants, non d'oreilles, mais des pupilles des yeux ("arracadas de sus niñas ") et la mer de larmes que Dorotea prétend verser se mue, dans les propos de Fernando, en un océan : celui qui sépare l'Espagne des Indes d'où vient d'arriver le nouvel amant riche de Dorotea, don Bela. Ses larmes ne sont, en réalité, que le masque éphémère du rire ("entretelas de la risa "), et elles sèchent plus vite qu'un orage d'été ${ }^{18}$. Mais le jeu cruel des amours finissantes, des regains amoureux suivis de ruptures et de regrets ou de colères culmine à la fin de l'œuvre (V, 3-4), lorsque les larmes vraies de Dorotea, humiliée en public par son amant, sont diminuées en lagrimillas :

Fer: Referiros el coloquio era cansaros. Habló con celos, respondi sin amor; fuese corrida y quedé vengado; y más cuando vi las lagrimillas, ya no perlas, que pedian favor a las pestañas para que no las dejasen caer al rostro, ya no jazmines, ya no claveles $^{19}$.

Fernando supprime toute qualité poétique aux larmes en utilisant le diminutif lagrimillas, mais aussi en niant leur potentiel métaphorique ( $y a$ no perlas), de même qu'il le refuse à son visage, qui n'est plus ni jasmins ni œillets. Mais s'il s'est vengé, la peine de Dorotea, qui retient autant qu'elle le peut ses larmes (elles «supplient les cils de ne pas les laisser rouler sur les joues ") en acquiert une dimension pathétique nouvelle.

Dorotea, qui se complaît dans l'épanchement en faisant des larmes un produit de beauté (" agua de rostro »), se voit renvoyer par Gerarda une image des larmes tout autre : elle doit faire pénitence après avoir été séduite par les artifices menteurs de son amant Fernando, que la vieille entremetteuse ridiculise comme peu virils ou enfantins ("lagrimillas mujeriles, suspiros a medio puchero ") :

Ger.: ¿Tienes juicio, Dorotea? ¿Qué es esto? ¡Tú llorando todo el día! [...] ¿Tú por lavar la cara?

Dor.: Déjame, tía; que no hay agua de rostro como las lágrimas. [...]

Ger.: [...] bien sé yo que no lloras por penitencia, sino por no haberla hecho. [...] Bien sé yo de qué tienes [arrepentimiento]. De haber

18. Dorotea se remémore sa mise en scène après le départ de Marfisa venue la voir chez elle (III, 3) : "Gustos ajenos ocupaban tus brazos, cuando mis ojos lágrimas en las violencias de una madre airada? No más, injustísimo amor, no más; hoy sale Fernando de mi pecho, como espiritu a los conjuros desta mujer. " (La Dorotea, p. 162). Piquée au vif par la jalousie, elle prend conscience de l'inanité de son masque de pleurs.

19. La Dorotea, p. 448. 
empleado mal tanta hermosura, tan rico entendimiento y tantas gracias. [...] a vosotras la invención os engaña, el embeleco y la elevación, las lagrimillas mujeriles, los suspiros a medio puchero ${ }^{20}$.

Ainsi, le langage des larmes n'est pas univoque : comme un trait d'union entre la mise en scène et le cri du cœur, la rage et l'hommage tempéré, les larmes deviennent une sorte de suprême concepto. Le réseau sémiotique des larmes permet, à la fois, de condenser les différentes étapes de l'histoire de la rupture amoureuse entre les deux protagonistes et d'établir un parallèle sans équivoque avec le désespoir de l'auteur après la mort de sa dernière maîtresse.

\section{LES LARMES EN TANT QUE CONCEPTO:}

LE TOMBEAU DU PHÉNIX AMOUR

En contraste avec les larmes comme artifice littéraire du movere, les larmes funèbres apparaissent surtout dans les pièces lyriques composées à la mort de Marta de Nevares et dans les fragments dialogués voisins. La série des trois premières barquillas foisonne d'évocations élégiaques dont les larmes versées à la mort d'Amarilis sont l'instrument. Le premier poème-hommage (III, 1) de "un gentilhombre [al que] se le ha muerto su dama" ("Ay soledades tristes»), est celui qui contient le plus grand nombre d'occurrences du champ sémiotique des larmes:

O ¿pediréllorando

[...]

Ayudad con suspiros

Mis lastimosas quejas.

El, que a la mar saliere,

[...]

Embárquese en mis ojos,

$[\ldots]$

Yel que mejores rimas

Hiciere a las exequias

De mi querida esposa,

[...]

Para que doble el llanto

Tan mísera tragedia.

[...]

20. La Dorotea, p. 456-457. 
Lo que la voz solía,

Las lágrimas celebran.

$[\ldots]$

Las lágrimas la miran,

[...]

Así lloraba Fabio

[...]

La vida de Amarilis,

La muerte de su ausencia.

Cuando atajaron juntas

[...]

El corazón las ansias,

Las lágrimas la lengua.

Les occurrences relevées sont augmentées de l'évocation de la plainte ("lastimosas quejas"), de la complainte (" tristes endechas"), de la tristesse ("inmortal tristeza "), de l'élégie (" miseras elegias»), des obsèques (" exequias de mi querida esposa"), de la tragédie (" misera tragedia ") ${ }^{21}$.

La deuxième barquilla ("Para que no te vayas "), est close par les vers suivants :
A cuanto me dijeron
Llorando satisfice:
[...] quiero yo que el alma
Llorando se distile
Hasta que con la suya
Esta unidad duplique;
Que puesto que mi llanto
Hasta morir porfie,
Tan dulces pensamientos
Serán después fenices ${ }^{22}$.

Les pleurs deviennent l'essence de l'âme et ils permettront à l'amour, qui l'occupe tout entière, de renaître de ses cendres à l'image du phénix. La même évocation introduit l'interprétation de la troisième barquilla ("Pobre barquilla mía ", III, 7) :

21. La Dorotea, p. 218-221-224-225-226. Fernando en vient à jalouser le poète dont la dame est morte : "Fer. : Con tanta acción has leido, Julio, esos versos, que me has traido las lágrimas a los ojos. [...];Pluguiera a Dios que yo llorara a Dorotea! [...] ;Oh, si pudiéramos trocar tristezas! Que él llora lo que le falta, y yo lo que tiene otro. " (La Dorotea, p. 227-228)

22. La Dorotea, p. 236. 
Jul.: [...] [t]oma el instrumento y canta, siquiera porque diviertas tanta tristeza; [...] y por ventura echarás de ver si ha quedado alguna centella en las cenizas de aquel fuego, para que el fénix amor salga a segunda vida [...] después que ha hecho su sepulcro o nido sobre las lágrimas de mirra... ${ }^{23}$.

Lâme, délestée par la poésie de sa peine, n'est plus qu'amour immortel. La quatrième et dernière barquilla "Gigante cristalino " (III,8) ne contient significativement aucune référence aux larmes : [Fabio] " ya no repara en nada ", le refrain réitère l'indifférence à tout, tant la peine a été grande et durable : "Mas tanto pueden tristezas / De pasadas alegrias, / Que obligan, si porfian / A no estimar la muerte ni la vida " ${ }^{24}$. Les larmes funèbres disparaissent pour laisser place à la renaissance du phénix amour.

Le concepto amoureux suprême de l'œuvre, "piedra imán " ${ }^{25}$ de l'ensemble des pièces lyriques, est le tombeau de larmes construit dans le sonnet de l'acte IV "Aqui, donde jamás tu rostro hermoso ". Rapprochant de façon inusitée le solide et le liquide, cette épitaphe est composée par Fernando au portrait de Dorotea qu'il enterre symboliquement pour signifier son désamour. Or, le récit de l'enterrement de l'amour est enchâssé dans une situation où les deux amants sont en présence physique l'un de l'autre, puisque Fernando raconte son histoire à Felipa et à Dorotea masquée ${ }^{26}$ et qu'une réconciliation fugitive suivra le récit. Le sonnet évoque dans son dernier tercet la vanité de l'enterrement de l'amour qui renaît de ses cendres comme le phénix.

"Aqui donde jamás tu rostro hermoso" est point le culminant d'une série de poèmes de séparation qui reviennent sur la décision de rupture ${ }^{27}$. La dernière folie de l'amant (" quiero deciros un desatino que hice ", p. 290) est l'acte symbolique de l'enterrement du portrait de Dorotea, comme une mise à mort sublimée :

Fer. Saqué el retrato desta dama, que envuelto en un tafetán traía en un naipe; [...]. Finalmente determiné de quitarme la ocasión de

23. La Dorotea, p. 290.

24. La Dorotea, p. 299.

25. La Dorotea, p. 170.

26. Au Prado, Felipa et Dorotea aperçoivent Julio et Fernando. Felipa, qu'ils ne connaissent pas, interpelle les deux hommes et persuade Fernando de raconter l'histoire de sa vie en présence de Dorotea, cachée sous un voile : «Fel. [...] entreteneos a vos mismo con referir la historia de que os quejáis; que los enfermos de vuestro mal darán dineros porque los escuchen." (La Dorotea, p. 313).

27. Dans le résumé de son histoire d'amour qu'offre Fernando tout au long de la scène 1 de l'acte IV, il récite successivement : «Si vas conmigo, Amarilis» (p. 327), "Cuidados, ¿qué me queréis? » (p. 329), «En una peña sentado » (p. 331). 
tantas penas, porque ya no me servía de consuelo, sino de desesperación, y sacando la daga...

Fel. jJesús! ¿Mataste a Dorotea? ${ }^{28}$

Tout reste ainsi dans le domaine du symbolique : Fernando enterre son amour sous la forme du portrait ; il compose un sonnet en guise d'épitaphe mais celle-ci n'est ni écrite sur un billet, ni gravée dans la pierre ou sur l'écorce d'un arbre (comme le veut la tradition littéraire) :

Fer. [...] Cavé la poca tierra que en el espacio de dos peñas estaba ociosa, y enterré el retrato, habiendo hecho primero estos versos:

Aqui donde jamás tu rostro hermoso

Planta mortal, divina Dorotea,

Toque atrevida, tu sepulcro sea,

Sin columnas de pórfido lustroso.

El fénix yace en inmortal reposo;

No vuelva a renacer ni el sol le vea,

Construyéndole, en vez de urna sabea,

Mis lágrimas pirámide oloroso.

Mas ¿qué importa, si amor inmortaliza

El único milagro que deshace,

$Y$ a más eterno sol la pluma enriza?

Remedio inútil entre peñas yace,

Si el alma que abrasa en la ceniza

Infante fénix del difunto nace ${ }^{29}$.

Alors que Dorotea, dont le nom apparaît pour la première fois dans un poème, est associée au phénix, l'oiseau mythique qui renaît de ses cendres, le poète souhaite un impossible : sa mort définitive. En enterrant le portrait de Dorotea, Fernando croit qu'il va enterrer son amour, ce qui se révèle tout aussi impossible ${ }^{30}$.

Seul le premier quatrain est adressé directement à Dorotea ; le dernier vers du second quatrain et le premier tercet introduisent le je lyrique. Le concepto qui rapproche le souhait de la mort du phénix et le constat

28. La Dorotea, p. 331-333.

29. La Dorotea, pp. 331-333.

30. Nous reprenons les notes prises lors du cours de Nadine Ly consacré au commentaire de ce sonnet conceptiste. Nadine Ly, "Lope de Vega entre deux genres : La Dorotea », Cours inédit de CAPES et d'agrégation, Université Michel de Montaigne-Bordeaux III, 2001-2003. 
de la vanité absolue de ce souhait affleure dans l'absence de géométrie structurelle du sonnet.

Dans le premier quatrain, "Aquí " est à comprendre à la fois comme le lieu où le portrait est enterré et comme le poème lui-même. La fonction syntaxique de "tu rostro hermoso " est mise en suspens dans un premier temps. "Planta mortal» signifie littéralement "planta del pie ». Le portrait est enterré dans un lieu sacré et le tombeau est défini en négatif : c'est un sépulcre sans colonnes (vers 3-4). La restitution grammaticale du quatrain reviendrait donc à cela : 'Aqui donde jamás planta mortal toque tu rostro hermoso, divina Dorotea, tu sepulcro sea sin columnas de pórfido lustroso'.

Le phénix apparaît au deuxième quatrain. Au pied de la lettre, il est l'oiseau dont le repos n'est pas comparable à la mort ("inmortal reposo ", vers 5), mais aussi métaphoriquement le portrait que l'on vient d'enterrer, c'està-dire métonymiquement Dorotea. Le vers 6 pose l'impossible : "No vuelva a renacer ni el sol le vea ". La définition du sépulcre se poursuit, aux vers 7 et 8 , avec le refus du vase parfumé, du bûcher du phénix (le feu) auxquels est préférée la proposition "pirámide oloroso " (les larmes). Le sonnet est ainsi défini comme un tombeau de larmes, odorant, parfumé.

La question rhétorique du premier tercet démonte le paradoxe : peu importe l'impossible, la solution extraordinaire est dans le retour à la doxa, à la croyance traditionnelle : l'amour immortalise ce qu'il enterre. Le vers 11 fait ensuite une double allusion à l'oiseau et à l'écriture : l'oiseau gonfle ses plumes au soleil et la plume du Poète reprend des forces dans la lumière.

Finalement, peu importe que le portrait soit enterré ; il subit, dans le deuxième tercet, une dernière métamorphose : l'amour est le phénix (c'est-àdire Dorotea et, en dernière instance, le sonnet) qui a brûlé dans le bûcher de l'âme et qui renaît de ses cendres. Dorotea est devenue immortelle, comme elle l'avait souhaité à la scène 2 de l'acte II :

Dor. ¿Qué mayor riqueza para una mujer que verse eternizada? Porque la hermosura se acaba, y nadie que la mira sin ella cree que la tuvo; y los versos de su alabanza son eternos testigos que viven con su nombre. La Diana de Montemayor fue una dama natural de Valencia de Don Juan, junto a León. Y Esla, su río, y ella serán eternos por su pluma. Así la Fílida de Montalvo, la Galatea de Cervantes, la Camila de Garcilaso, la Violante del Camoes, la Silvia de Bernaldes, la Filis de Figueroa, la Leonor de Corte Real ${ }^{31}$.

Dorotea est immortelle pour Fernando par la grâce du tombeau, monument à la vie éternelle, hors de la chronologie diégétique. Au-delà de

31. La Dorotea, p. 153. 
la situation textuelle et à la lumière de la réplique de Dorotea, qui souligne que le fait de chanter sa bien-aimée même après la mort de celle-ci grandit le poète, elle accède au rang des muses célèbres, immortalisées dans les vers, et avec elle, Fernando est élevé au rang des plus grands poètes.

Au-delà de la fiction, Lope de Vega érige son œuvre en tombeau de l'amour, grâce à une motivation renouvelée du topos des larmes funèbres. La célébration de l'aimée au-delà de la mort rappelle les nombreux poèmes dédiés à la mort d'Amarilis écrits par ce poète que tous les personnages admirent tant. Ainsi, le nom de Dorotea, loin de ne désigner que Elena Osorio, peut tout aussi bien renvoyer à Amarilis-Marta, comme le remarque Nadine Ly ${ }^{32}$.

Le sonnet du phénix amour prend la forme d'un concepto : le tombeau littéral, poème simplement proféré, sépulcre invisible de larmes, devient monument immortel. Le langage des larmes rappelle dans La Dorotea le planctus médiéval, lui-même héritier du chant XXIII de l'Iliade (Achille pleurant la mort de Patrocle) :

[...] Akhilleus [...] dit à ses braves compagnons :

- Myrmidones aux chevaux rapides, mes chers compagnons, [...] pleurons Patroklos, car tel est l'honneur dû aux morts. [...]

Il parla ainsi, et ils se lamentaient, et Akhilleus le premier. Et, en gémissant, ils poussèrent trois fois les chevaux aux belles crinières autour du cadavre ; et Thétis augmentait leur désir de pleurer. Et, dans le regret du héros Patroklos, les larmes baignaient les armes et arrosaient le sable ${ }^{33}$.

Le planctus (coups que l'on se porte en signe de douleur; gémissements, lamentations $\left.{ }^{34}\right)$ se trouve défini dans ce passage. Le tombeau symbolique des

32. " [Le sonnet en forme d'épitaphe] relève également de la mémoire circonstancielle et autobiographique de la mort d'Amarilis, qui peut prendre ici le nom de Dorotea, de la même manière que, partout ailleurs, le nom de la transposition poétique de l'héroïne de l'action en prose était Amarilis. " in Nadine Ly, "Mémoire théorique et mémoire de l'âme : La matière de poésie et la poésie de la matière dans La Dorotea de Lope de Vega ", Lectures d'une auvre : La Dorotea de Lope de Vega, Collectif coordonné par Nadine Ly, Paris, Éditions du Temps, 2001, p. 210).

33. Homère, L'Iliade, Chant XXIII, traduction de Leconte de Lisle, 1818-1894, URL : http://philoctetes.free.fr/ilchant23.htm. "Depuis l'Iliade, où Achille pleure la mort de Patrocle, les proches du défunt improvisent un poème funèbre, qui devient la plainte, le planctus médiéval. L'Église des premiers siècles avait permis l'expression de ces grandes douleurs, car elle se devait d'hériter de la tradition païenne de la consolation pour lui substituer la sienne, pour annoncer un Dieu consolateur. À l'encontre des stoïciens, elle doit admettre les larmes. " (Roth, op. cit., p. 34)

34. Félix Gaffiot, Dictionnaire latin-français, Paris, Hachette, 1934. L'expression de la 
pleurs sert ainsi à la fois d'exutoire et d'expression de l'impossible deuil. Les larmes sont une humeur qui console, mais elles sont également une encre indélébile, un instrument de mythification. Dans La Dorotea, l'expression de la douleur est à la fois manifeste et en sourdine. L'encre indélébile des larmes, présentes partout de façon diffuse, fait de l'œuvre toute entière un planctus retenu, contenu, écrit à la gloire de l'être aimé et à la gloire de soi.

\section{BibliograPHIE}

Barthes Roland, Fragments d'un discours amoureux, Paris, Seuil, 1977.

Gaffiot Félix, Dictionnaire latin-français, Paris, Hachette, 1934.

Homère, L'Iliade, Chant XXIII, traduction de Leconte de Lisle, 1818-1894, URL : http://philoctetes.free.fr/ilchant23.htm.

Lope de Vega, "Égloga a Claudio ", in Rimas humanas y otros versos, ed. de Antonio Carreño, Crítica, Barcelona, 1998.

- La Dorotea, Madrid, Clásicos Castalia, 1980.

Ly Nadine, «Lope de Vega entre deux genres : La Dorotea », Cours inédit de CAPES et agrégation, Université Michel de Montaigne-Bordeaux III, 2001-2003.

- «Mémoire théorique et mémoire de l'âme : La matière de poésie et la poésie de la matière dans La Dorotea de Lope de Vega ", Lectures d'une æuvre : La Dorotea de Lope de Vega, Collectif coordonné par Nadine Ly, Éditions du Temps, Paris, 2001.

- «Présentation», in Lope de Vega, La Dorotea, Traduction par Yves Roullière, Présentation par Nadine Ly, Paris, GF Flammarion, 2006, p. I- LI.

Maravall José Antonio, Utopía y contrautopía en el Quijote, Madrid, Visor Libros, 1976.

Montemayor Jorge de, La Diana, Barcelona, Crítica, 1996.

Roth Danielle, Larmes et consolations en France au XVII siècle, Lyon, Éditions du Cosmogone, 1997.

douleur est à la fois manifeste et en sourdine. 


\section{RELEVÉ DES OCCURRENCES DU CHAMP SÉMIOTIQUE DES LARMES}

\section{PRÓLOGO «AL TEATRO»}

p. 63: ... las lágrimas de la honra

ACTO I

Escena 2:

p. 87: Teo.: ... ¿Lloras? Bien haces...

Escena 4:

p. 99: "A mis soledades voy": ...Llorando van y pidiendo.

Escena 5:

p. 104: Fer.: ...Mira, Julio, ¡qué lágrimas! Parece azucena con las perlas del alba. [...] Dor.: ... que la mujer más fuerte al fin es obra imperfecta de la naturaleza, sujeto del temor y depósito de las lágrimas.

p. 107-108: Dor.: ...ese crocodilo gitano, que llora y mata; [...] Déjame deshacer estos ojos, pues ya no son tuyos... [...] Fer.: ...Vuelve a serenar los ojos, suspende las perlas, que ya parecían arracadas de sus nińas.

p. 110: Dor.: El [mar] de mis lágrimas. Fer.: Las de las mujeres son entretelas de la risa.

p. 117: "Zagala asi Dios te guarde": A tus ojos me subiste; / En ellos vi cómo llueven, / Cuando quieren, perlas vivas, [...] Habrá lágrimas que mienten. / Los hechizos de tu llanto / Divinamente me prenden, / Pues mis ojos de los tuyos / Veneno de perlas beben. / Tus lágrimas me aseguran, [...] Tres días ha que te fuiste [...] / Dejando las [fuentes] de mis ojos, [...] / ¿En qué mejores cristales / Quien ama mirarse puede, / Si espejos del alma vivos / Fueron las lágrimas siempre? [...] / Antes que mire otros ojos, / Los míos llorando cieguen.

Escena 6:

p. 128: Fer.: [...] ¿Lloras por mí o por el muerto? Mar.: Lloro por entrambos.

p. 129: Fer.: No llores, Marfisa mía; que no acertaré a partirme. Porque no hay rémoras para detener un alma como las lágrimas de lo que se adora. Mar.: En tu rostro las estampo, a efeto de que te acuerdes que las lloraron mis ojos casi en los tuyos, por engañarme de que eran tuyas. Fer.: Alguna mía se ha mezclado en ellas...

p. 130: Cla.: Mi ama llora; voy a consolarla. 


\section{ACTO II}

Escena 1:

p. 147: Bel.: ¿Por eso lloras? Ger.: Soy tan devota, que en hablando en el Señor, no puedo contener las lágrimas. Lau.: Todo aquello es vino. Bel.: No llores, madre. Lau.: Sálese el cuero.

Escena 3:

p. 158: Dor.: [...] [la engañaba] con amores, con caricias, [...] y con lágrimas. Mar.: ¿Lloran los hombres? Dor.: Este [...] decía que ya él no era hombre; porque, transformado en su dama, había perdido el ser, y podía tener con disculpa esta condición; que en las mujeres [...] las lágrimas son piedad, hermosura y consuelo, como mayorazgo de su imperfección. Mar.: Si él las llorara por vos, disculpado estaba...

p. 162: Dor.: [...] ¿¿Gustos ajenos ocupaban tus brazos, cuando mis ojos lágrimas en las violencias de una madre airada?

p. 166: "Al son de los arroyuelos": Y mientras que lloro yo / Las penas que amor me dio / [...] Al son de los arroyuelos / Cantan las aves de flor en flor...

Escena 4:

p. 174: "Así Fabio Cantaba": Así Fabio cantaba [...], / Oyéndole las aguas, / Llorándole las ninfas. [...] p. 176: / Ya lloraba el aurora, / Y abriendo clavellinas, / Como miraban perlas, / Pensaban que era risa;...

Escena 6:

p. 204: Teo.: Gerarda, no bebas más, que dices desatinos. [...] ¿Para qué lloras?

p. 210: Cel.: En los ojos tienes eso postrero [el arrope, una especie de jarabe concentrado], como has llorado.

p. 214: "Coro de Interés": Amor a Venus cándida, / [...] Lloró con tiernas lágrimas.

\section{ACTO III}

Escena 1:

p. 218: "Ay soledades tristes": O ¿pediré llorando [...] / Ayudad con suspiros / Mis lastimosas quejas. / El, que a la mar saliere, [...] / Embárquese en mis ojos, [...] / Y el que mejores rimas / Hiciere a las exequias / De mi querida esposa, [...] / Podrá suspiros míos, [...] Para que doble el llanto / Tan mísera tragedia. [...] / Lo que la voz solía, / Las lágrimas celebran. [...] / Las lágrimas la miran, / [...] Así lloraba Fabio / [...] La vida de Amarilis, / La muerte de su ausencia. / Cuando atajaron juntas / [...] El corazón las ansias, / Las lágrimas la lengua.

p. 228: Fer.: Con tanta acción has leído, Julio, esos versos, que me has traído las lágrimas a los ojos. [...] ¡Pluguiera a Dios que yo llorara a Dorotea! [...] ¡Oh, si pudiéramos trocar tristezas! Que él llora lo que le falta, y yo lo que tiene otro.

p. 232: "Para que no te vayas": Aun no mostraba el alba / Sus cándidos perfiles, 
[...] / Llorando en alelíes. / [...] Con lágrimas repite / Mi voz tu dulce nombre, [...] / «No os admiréis, les digo, / Que llore y que suspire / Aquel barquero pobre [...] / Ya mi amado instrumento / Lloró por infelices [hazañas invencibles], [...] / A cuanto me dijeron / Llorando satisfice: [...] / Que quiero yo que el alma / Llorando se distile [...] / Que puesto que mi llanto / Hasta morir porfíe, / Tan dulces pensamientos / Serán después fenices.

Escena 4:

p. 252: Lud.: ...Habló poco [...] y no sin alguna lágrima...

Escena 6:

p. 280-281: Dor.: [...] Toda fui lágrimas hasta tu casa [...] Lo más que me dijiste para consolar mis lágrimas fue hacerme cargo de que por mí no estabas casado [...]. Secásteme con tu sequedad las lágrimas, [...] si [e]sta [carta] llega a tus manos, se la comunicarás con risa a quien se estará burlando de mis lágrimas...

Escena 7:

p. 287: Fer.: Ese soy, Julio, que vivo y muero templando con mis lágrimas este vivo ardor que me consume.

p. 290: Jul.: ... para que el fénix amor salga a segunda vida [...] después que ha hecho su sepulcro o nido sobre las lágrimas de mirra...

p. 293: "Pobre barquilla mía": No quieras que yo sea / [...] Faetonte de barqueros, / Que los laureles lloran. / [...] Cuando de rojo nácar / Se afeitaba la aurora, / Más peces te llenaban / Que ella lloraba aljófar. [...] La muerte nos divorcia: / ¡Ay de la pobre barca / Que en lágrimas se ahoga!

Escena 8:

p. 304: Fer.: [...] este pescador lloraba la más hermosa mujer...

Escena 9:

p. 306 "Coro de celos": Por quien la blanca Aurora / Tierno mana sobre las flores llora...

ACTO IV

Escena 1:

p. 316: Fer: [...] lloramos los dos detrás de una puerta, mezclando las palabras con las lágrimas; tanto que apenas supiera quien nos mirara cuáles eran las lágrimas o las palabras. Fel.: Gran llorador debéis de ser. Fer.: Tengo los ojos niños y portuguesa el alma.

p. 320: Fel.:[...] ¡Ay, hombres! ¡Qué presto se le enjugaron las lágrimas y se le olvidó la salva de la boca a la sombra de la puerta!

p. 325: Fer.: [...] no pudiendo cubrir aquellas hermosas manos con diamantes, las bañaba en lágrimas...

p. 326: Fer.: [...] Diome Marfisa el oro que tenía y, las perlas de sus lágrimas, y con él me partí a Sevilla. 
p. 327: Fer: Partíme a ver el mar [...] y díjele lo que había oído a un poeta: Bebérmele quisiera / Por volverle a llorar, si yo pudiera [...].

p. 333: Fer.: "Aquí donde jamás tu rostro hermoso": Mis lágrimas pirámide oloroso.

p. 335: Fer.: [...] Suplícoos, señora mía, que me perdonéis; que se me ha cubierto el corazón y los ojos de agua.

p. 336: Fel.: [...] ya vuelve Fernando con la bebida de tus amorosas lágrimas. [...] Fel.: Trae este búcaro de agua. Dor.: ¿Para qué, Felipa, donde están mis lágrimas?

p. 340: Dor.: [...] te perdonaré un bofetón que un día me diste [...] agravio que tú lloraste mucho tiempo...

Escena 3:

p. 363: Jul.: Ausentóse Fernando, / juró, mintió, volvió, rogó llorando.

p. 383: Jul.: ¡Qué dulce almíbar masco / Cuando lleno de cólera me rasco! / Porque parece, aunque después lo lloro, / Que ensarto por las uñas granos de oro.

Escena 6:

p. 400: Dor.: ¡Oh, madre! Si le hubiera oído [el supuesto sermón, en realidad reencuentro con Fernando], no pudiera detener las lágrimas. Teo.: Como esas he llorado yo por su paternidad de ese bendito predicador.

p. 401: Dor.: Hoy, Felipa, ni pienso llorar, ni reñir; [...] Yo vi lágrimas en Fernando cuando más desconfiaba de su memoria...

p. 403: Ger.: [...] ¿Qué sermón oye donde no llore [Felipa]?

Escena 7:

p. 405: "Adónde váis pensamiento": Si en lágrimas os fiastes, / Presumid que no fue llanto, / Sino escribir en el agua / La fe del amor pasado.

Escena 8:

p. 409: Jul.: No le dejaron acabar las lágrimas [a Marfisa]. [...] También llora Clara y yo estoy consultando los pucheros... Mar.: [...] Muchas lágrimas me cuestas, Fernando, muchos trabajos, dulce enemigo mío. [...] Fer.: Espera, señora, espera. Por lo menos, no te vayas llorando.

p. 410: Fer.: ...Y como quien para que una cosa se limpie la baña en agua, así lo quedé yo en sus lágrimas de mis deseos. [...] Jul.: ...tantos amorosos afectos, desmayos, ansias, locuras, desesperaciones, celos, deseos y lágrimas han tenido templanza en su mismo centro, lo que parece imposible.

\section{ACTO V}

Escena 2:

p. 418: Bel.: Madre, luego lloras; no he visto ojos tan tiernos. Dale cuatro reales, Laurencio. 
p. 430: "Si tuvieras, aldeana": No gastes mal tantas perlas, / No llores más, no me mates; [...] / No lloréis, ojuelos, / Porque no es razón / Que llore de celos / Quien mata de amor.

Escena 3:

p. 448: Fer: [...] cuando vi las lagrimillas, ya no perlas, que pedían favor a las pestańas para que no las dejasen caer al rostro, ya no jazmines, ya no claveles.

Escena 4:

p. 456-457: Ger.: [Dorotea] ¡Tú llorando todo el día! [...] Dor.: Déjame, tía; que no hay agua de rostro como las lágrimas. [...] Ger.: [...] bien sé yo que no lloras por penitencia, sino por no haberla hecho. [...] a vosotras la invención os engaña [...] las lagrimillas mujeriles, los suspiros a medio puchero [...] Dor.: Mientras un hombre no tiene bozo, no le están mal las lágrimas; que los hombres no lloran descompuestos, sino con dulce embuste. [...] Ger.: Niña, niña, las mujeres no han de saber de historias ni de lágrimas, sino de hacer vainillas. Dor.: [...] Dor.: [...] consuela a mi madre, que está llorando de verme triste, y entretenla mientras escribo dos palabras.

p. 459: Dor.; Porque si agora esta vitoria la provoca a risa, desde los acentos della la convido a las mismas lágrimas.

Escena 9:

p. 479: Dor.: [...] Mi amor paró en celos, mis celos en furia, mi furia en locura, mi locura en rabia, mi rabia en deseos de venganza, mi venganza en lágrimas y mis lágrimas en arrojar por los ojos el veneno del corazón.

Escena 10:

p. 489: Ger.: [...] De desmayarse a su tiempo y llorar sin causa.

p. 490: Ger.: [...] Las lágrimas me has traído del corazón a los ojos. Conozco, aunque tarde, mis engaños.

Escena 11:

p. 491: Dor.: ¡Ay, Dios, Laurencio! Si no te viera las lágrimas en los ojos, [...] no pudiera persuadirme a que no me engañaban tus palabras. Pero ¿qué palabras con lágrimas no fueron verdaderas en los hombres? [...]Gerarda y yo lloraremos por ti. Ger.: ¡Y cómo si lloraremos! Habla, hijo, que tienes nuestras vidas colgadas en el hilo del agua de tus lágrimas. Lau.: ¡Ay, Dorotea! [...] soy trágico y desdichado nuncio, más lloroso y con más razón de dolor que en el Hipólito de Séneca. [...] No sé cómo [hablar] si no desocupa el camino a la lengua [...] el confuso tropel de los sollozos y el espeso diluvio de las lágrimas. [...] Ger.: ¡Ay, Laurencio! [...] bastaban las palabras sin las lágrimas, y los sentimientos sin los sollozos.

Escena última:

p. 494: Dor.: Madre, [...] Mire ese afligido mozo llorando, y sabrá que su señor don Bela es muerto. 